\title{
INTERLAMINAR AND INTRALAMINAR DAMAGE MECHANISMS OF IMPACT RESISTANT AIRCRAFT MATERIALS UNDER LOW-ENERGY IMPACT
}

\author{
N. Keršienė, A. Žiliukas \\ Department of Mechanics of Solids, Kaunas University of Technology, Kęstučio 27, LT-44025 Kaunas, Lithuania \\ E-mail: neringa.kersiene@stud.ktu.lt,e-mail: antanas.ziliukas@mf.ktu.lt \\ Received 1002 2006, accepted 07092006
}

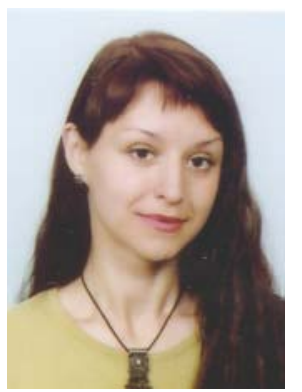

Neringa KERŠIENĖ, M.Sc. Eng.

Date and place of birth:1976, Kaunas, Lithuania.

Education: 2002 - M.Sc. (Eng.) degree in Material Science, Kaunas University of Technology, Faculty of Mechanical Engineering.

2002 to present: Ph.D. studies, Kaunas University of Technology, Department of Mechanics of Solids.

Experience: work in field of material data evaluation for FEM simulation of polymeric materials in crash simulation, FEM model generation.

Training: Munich University of Applied Sciences, Germany.

Research interest: meso-mechanical failure modeling of crimp fabric composites for prediction of delamination, mixed Mode I-II and III fracture resulting from transverse impact.

Publications: author and co-author of five scientific articles and conference papers.

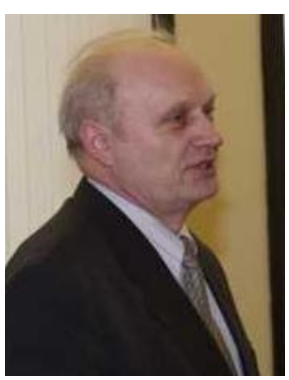

\section{Antanas ŽILIUKAS, Prof Dr Habil}

Date and place of birth: Zarasai, Lithuania, 1940

Education: Kaunas Polytechnic Institute; Mechanical Engineering Diploma (1963), Doctor Sc. Eng. Degree (1968), Doctor Habilitus Degree in Eng. (1989).

Fields of research: Mechanics of Solids, reliability of structures.

Present Position: Head of Department of Mechanics of Solids, Professor of Kaunas University of Technology, and member of Lithuanian Academy of Science.

Publications: monographs: "Fracture of structures", "Energomechanics" and textbooks: "Mechanics of deformable bodies" (I - 1994, II - 1995), "Technical diagnostics and reliability of aircraft", author and co-author over 200 scientific papers.

\begin{abstract}
For low-velocity impact, drop-weight impact tests performed by EADS (European Aeronautic Defence and Space Company) Corporate Research Center Germany have been carried out for 2-D woven E-Glass/epoxy composite systems to determine material response as a function of absorbed energy and damaged area. Nondestructive techniques like visual inspection and analysis of impact response of the woven fabric laminates at different energy levels are utilized to assess the initiation and progression of interlaminar and intralaminar damage. The dominant damage modes for woven reinforced composite systems were found to be matrix cracking with branching into the adjacent layers, intralaminar cracking by mixture of localized matrix shear and matrix/fibre interfacial debonding, front face indentation, and back face fibre damage. The use of woven fabrics as opposed to cross-ply unidirectional prepreg tapes is specifically discussed from the point view of microstructure and property. In the case of low-energy impact, damage resistance under impact loading of woven and multiaxial non-crimp fabrics is presented and compared. The assumption that shear-response dominated for woven reinforced composite systems was found to be in good agreement with the experimental results.
\end{abstract}

Keywords: impact, damage modes, delamination, woven fabrics, matrix cracking, impact energy, damage resistance.

\section{Introduction}

Due to low weight, high specific stiffness, and strength, fiber-reinforced laminated composite materials are now used extensively in many fields of engineering such as aerospace, automobile, and shipbuilding. These composite structures undergo various loading conditions during their service life. Among them, the most critical condition is impact loadings, due to the laminated nature of these structures. Fibre reinforced plastic composite materials are very susceptible to transverse impact damage both in terms of resistance and tolerance. As a result of impact or a manufacturing defect, interlaminar damage can cause a significant reduction in the residual tensile and, especially, compressive strengths after impact 
(CAI). They are the some of the most important characteristics of composite materials [8].

The development of epoxy resins led to increased use of E-glass laminates in aircraft and helicopters for the manufacture of composite components such as wings, and virtually the entire airframe and fuselage of modern gliders are made of glass/epoxy composite materials. Although many mechanical and fatigue properties of glass/epoxy composites are lower than those of other materials, they generally have a superior ability to absorb energy during impact [2]. However, these materials are sensitive to impact damage, especially out-of-plane impact, which can induce damage event at very low impact energies. The investigation of damage mechanisms taking place in E-glass/epoxy composite laminates subjected to low-energy impact loading is considered in this study. The high variability of handlaminated materials adds to the interest of the already complex impact problem.

\section{Impact test of woven E-Glass/epoxy composite systems}

A twelve-ply panel was laminated by hand using epoxy resin L285 reinforced with E-Glass-fiber balanced woven roving at a fibre mass-fraction of $45 \%$. Table 1 shows the structure of the glass filament fabrics for the woven fabric E-Glass/epoxy composite. The laminated specimens are prepared by cutting out $150 \mathrm{~mm} \times 100 \mathrm{~mm}$ with a nominal thickness of $3.8 \mathrm{~mm}$ for impact testing.

Table 1. Structure of the glass filament fabrics

\begin{tabular}{|c|c|c|c|c|}
\hline Producer & Yarn type & Weave & Adhesion & $\begin{array}{c}\text { Areal } \\
\text { density } \\
\left(\mathrm{g} / \mathrm{m}^{2}\right)\end{array}$ \\
\hline \hline $\begin{array}{c}\text { Interglass } \\
92125\end{array}$ & $\begin{array}{c}\text { EC 9- } \\
68 \times 3 \mathrm{t} 0 * \\
\text { EC9-204Z }\end{array}$ & $\begin{array}{c}\text { Twill } \\
2 / 2\end{array}$ & $\begin{array}{c}\text { Finish } \\
\text { FK 144 }\end{array}$ & 280 \\
\hline
\end{tabular}

For low-velocity impact, a vertical drop-weight testing machine with maximum impact energy of $120 \mathrm{~J}$ was developed at EADS Corporate Research Center Germany. To measure the impact force and displacement history, a Kistler Press Force Sensor Type 9333 and a Heidenhain Displacement Sensor Type LIDA 100 are mounted. The force transducer has a force capacity of $50 \mathrm{kN}$. The tests were performed according to Airbus-Norm AIITM 10010 [1]. The specimen was clamped between steel plates (Fig 1) and the impactor is dropped from a known, variable height, and hence at a known incident velocity, onto a horizontally supported plate target. A variable mass attached to the impactor allows variation of the velocity at a given incident energy. The tip of the impactor has a hemispherical shape and is made of hardened steel $R_{m}=2000 \mathrm{MPa}$ according to EN 2760. The impactor head is $15.75 \mathrm{~mm}$ in diameter. The height of the impactor was maintained between $344 \mathrm{~mm}$ and $1140 \mathrm{~mm}$. Impact tests were performed with nominal impact energies between 16 and $28 \mathrm{~J}$ and impact velocities between 2.54 and $4.63 \mathrm{~m} / \mathrm{s}$.



Fig 1. Vertical drop-weight impact test according to AirbusNorm AIITM 1-0010

The post-processing of force-time and deflectiontime data enables the software to calculate the energy absorbed by the specimen. Nondestructive techniques like visual inspection can be particularly useful in the examination of initiation and prdamage ogression in composite systems.

\section{Results and discussions}

\subsection{Interlaminar and intralaminar damage energy}

In the low-velocity impact of glass-fibre composites, transverse matrix cracking, delamination, and fibre fracture are three dominant energy absorption mechanisms. Upon non-penetrating impact, the total impact energy can roughly be divided into two parts: the elastically stored energy in the composite plate, which is released after maximum deflection by rebounding of the laminate, and the energy absorbed in the composite laminate, which is available for damage and consequently controls the extent of damage.

$$
E_{\text {impact }}=E_{\text {elastic }}+E_{\text {absorbed }}
$$

A significant proportion of the incident energy in structures is also absorbed through elastic structural response. In the beginning of the impact event, the impact energy is transferred to the specimen. The energy absorbed by the structure during impact (Fig 2) can be calculated as

$$
E_{a b}=E\left(1-e^{2}\right)
$$

where $E$ is the initial kinetic energy of the impactor, and $e$, the coefficient of restitution, is found from the expression

$$
\int F(t) d t=m v(1+e)
$$

in which the impulse is equated to the change in momentum of the impactor [12]. Figure 2 shows the transferred energy on the structure of laminates and the contact force plotted against the impactor displacement. 
In the case of the non-perforating impact test, the maximum transferred energy of $6 \mathrm{~J}$ and maximum impact force of $3.08 \mathrm{kN}$ are located at the maximum impactor displacement of $4.22 \mathrm{~mm}$.

The experimental results for maximum deflection and maximum force, for different impact energies and velocities are presented in table 2 .

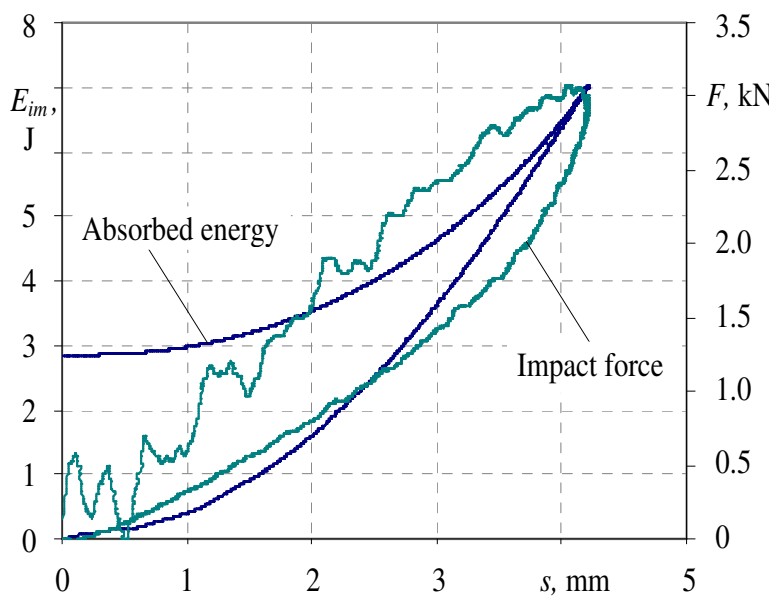

Fig 2. Absorbed energy and impact force plotted against impactor displacement by impact energy of $6 \mathrm{~J}$

\subsection{Impact damage resistance and damage modes of composite materials}

When the impactor strikes the specimens, the impacted composite material absorbs impact energy by elastic deformation if the incident energy is lower than a certain value. As the impact energy increases, matrix cracking occurs, and the interlaminar damage starts to propagate until the maximum delamination area has been reached. Thus, the dominant energy absorption mechanism is the delamination mechanism in the case of the low-energy non-perforating impact test.

Non-destructive damage evaluation methods used for opaque laminates include ultrasonic, X-ray and thermographic, but these methods are expensive and features may be obscured due to the non-homogenous nature of the material. Visual inspection of impacted specimens is utilized to assess the progression of damage. Damage in translucent laminates may be simply viewed by strong backlighting [9]. This gives the approximate damaged area, and also a qualitative description of the damage.

The interlaminar damage resistance under impact loading as a function of the absorbed energy was described by linear trends with the high coefficient of determination $R^{2}=0.99$ for woven fabric reinforcement and $R^{2}=0.94$ for multiaxial non-crimp fabric. Extrapolation of the data to zero absorbed energy yields an impact energy of around $0.2 \mathrm{~J}$, which is the energy necessary to initiate interlaminar damage in the case of the non-perforating impact test. The absorbed energy in the case of the low-energy impact tests of the specimens with woven fabrics reinforcement was approximately
$45 \%$ higher than that of specimens with multiaxial noncrimp (stitched) fabric reinforcement [7]. The undulating interlaced rovings of 2-D twill-woven fabric by transverse load requires more deflection to straighten and become fully loaded than cross-ply laminates.



Fig 3. Damaged area, plotted against the impact energy $\mathbf{J}$

The damaged areas, $D_{a}$, obtained by visual inspection of the specimens with woven fabrics and multiaxial non-crimp fabric reinforcement, are plotted as a function of the incident energy in figure 3 [6]. The increase in delaminated area with increasing impact energy is lower in the case of woven-fabric laminated specimens. These results agree with previous impact studies in which the higher impact damage resistance of woven fabrics laminates is connected with its interlaminar and intralaminar fracture resistance, which is higer than cross-ply laminates [4]. This reduced radial expansion of damage can be attributed to the selfconfinement of interlaced rovings.

The important reason for the enhanced fracture resistance of composite materials is the inherent roughness of woven fabrics. The inherently rough weave structure is particularly beneficial in limiting the propagation of shear cracks [11]. Created as a result of the roughness of woven fabrics are thick resin rich regions that can be found particularly at the inflection points of warp/weft yarns. The macroscopically rough, irregular fabric surface in woven-reinforced composite materials allows a significantly larger plastic yield zone to be developed ahead of the crack tip during interlaminar cracking $[3,5]$.

The many different damage modes observed by the experimental techniques used with composite laminates are presented in table 3. Some form of damage was observed at the very low incident energies. These modes form a complex overall damage pattern, but the progression of damage with increasing incident energy is similar for all specimens, and all of the main features may be described by categorizing the damage progression. The main features of the damage modes are now described for the front face, internal delamination, and back face damages of the woven fabric E-Glass/epoxy composite systems at impact energies between 6 and $28 \mathrm{~J}$. 
Table 2. Experimental results of low-energy impact tests

\begin{tabular}{|c|c|c|c|c|c|c|c|}
\hline $\begin{array}{c}\text { Low-Impact } \\
\text { Energy } \\
(\mathrm{J})\end{array}$ & $\begin{array}{c}\text { Impact } \\
\text { velocity } \\
(\mathrm{m} / \mathrm{s})\end{array}$ & $\begin{array}{c}\text { Contact } \\
\text { time } \\
(\mathrm{ms})\end{array}$ & $\begin{array}{c}\text { Max } \\
\text { force } \\
(\mathrm{kN})\end{array}$ & $\begin{array}{c}\text { By displ. } \\
(\mathrm{mm})\end{array}$ & $\begin{array}{c}\text { Max } \\
\text { defl. } \\
(\mathrm{mm})\end{array}$ & $\begin{array}{c}\text { Absorbed } \\
\text { energy } \\
(\mathrm{J})\end{array}$ & $\begin{array}{c}\text { Damage } \\
\text { area } \\
\left(\mathrm{mm}^{2}\right)\end{array}$ \\
\hline \hline 6 & 2.54 & 5.6 & 3.08 & 4.05 & 4.22 & 2.85 & 177 \\
\hline 10 & 3.25 & 5.7 & 4.09 & 5.10 & 5.29 & 5.18 & 283 \\
\hline 16 & 4.08 & 5.9 & 5.19 & 6.53 & 6.98 & 10.0 & 380 \\
\hline 22 & 4.11 & 6.1 & 5.20 & 6.06 & 7.17 & 11.2 & 415 \\
\hline 28 & 4.63 & 6.2 & 5.66 & 6.79 & 7.79 & 15.3 & 452 \\
\hline
\end{tabular}

Table 3. Damage modes for laminate

\begin{tabular}{|l|l|l|}
\hline $\begin{array}{l}\text { Fiber } \\
\text { dominated }\end{array}$ & $\begin{array}{l}\text { Matrix } \\
\text { dominated }\end{array}$ & $\begin{array}{l}\text { Interface } \\
\text { dominated }\end{array}$ \\
\hline \hline Fiber pull-out & $\begin{array}{l}\text { Transverse } \\
\text { cracking }\end{array}$ & $\begin{array}{l}\text { Interface } \\
\text { disbonding }\end{array}$ \\
\hline $\begin{array}{l}\text { Fiber tensile } \\
\text { failure }\end{array}$ & $\begin{array}{l}\text { Interlaminar } \\
\text { cracking }\end{array}$ & $\begin{array}{l}\text { Interface } \\
\text { delamination }\end{array}$ \\
\hline $\begin{array}{l}\text { Fiber micro- } \\
\text { buckling }\end{array}$ & $\begin{array}{l}\text { Intralaminar } \\
\text { cracking }\end{array}$ & $\begin{array}{l}\text { Compressive } \\
\text { delamination }\end{array}$ \\
\hline $\begin{array}{l}\text { Fiber shear } \\
\text { failure }\end{array}$ & $\begin{array}{l}\text { Edge } \\
\text { delamination }\end{array}$ & \\
\hline
\end{tabular}

\section{Front face damage}

The front-face damage in woven E-Glass/epoxy composite systems is presented in figure 4. At the low incident energy of $6 \mathrm{~J}$, a small permanent indentation occurs under the impactor. An area of delaminated zones forms on the front-face at the roving 'cross-over' points, which is small in comparison to the internal delamination. The internal and front-face delamination areas increase rapidly, whilst the permanent indentation becomes more severe. The front-face delamination with matrix damage becomes pronounced in a central cross-shaped area that follows the weave directions, and internal delaminations become irregular in shape. Contact force at 22 and $28 \mathrm{~J}$ causes front-face fibre shear-out failure.

\section{Back face damage and internal delamination}

In figure 5 the back-face and internal damage of low-velocity impact tests with nominal impact energies between 16 and $28 \mathrm{~J}$ are presented. The back-face damage consisted of a central area of matrix cracking and progressive degradation, and then associated fibre

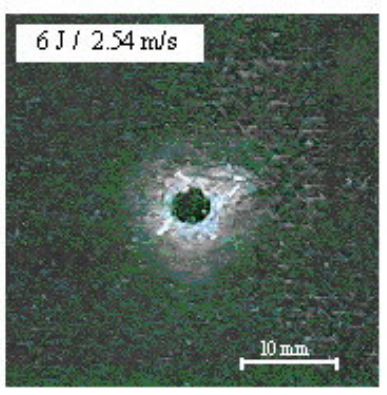

Specimen $2 / 1$

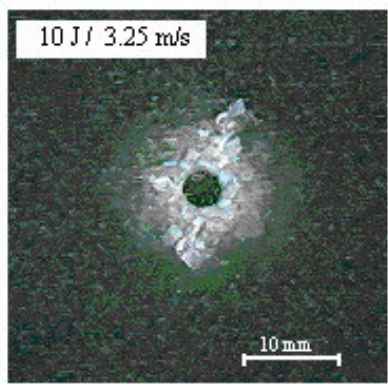

Specimen $2 / 2$

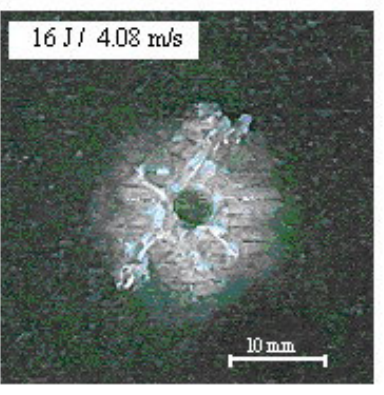

Specimen $2 B$

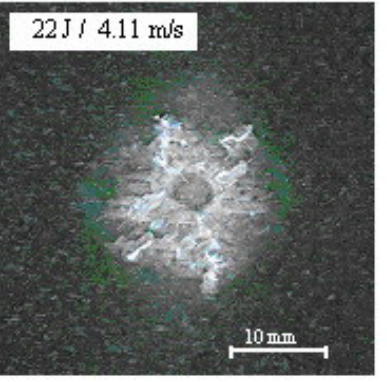

Specimen $2 / 4$

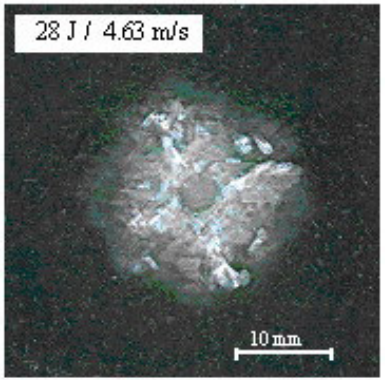

Specimen $2 / 5$

Fig 4. Front face view of woven glass-fiber reinforced composites showing damage modes at impact energies between 16 and $28 \mathrm{~J}$ and impact velocities between 2.54 and $4.63 \mathrm{~m} / \mathrm{s}$ 


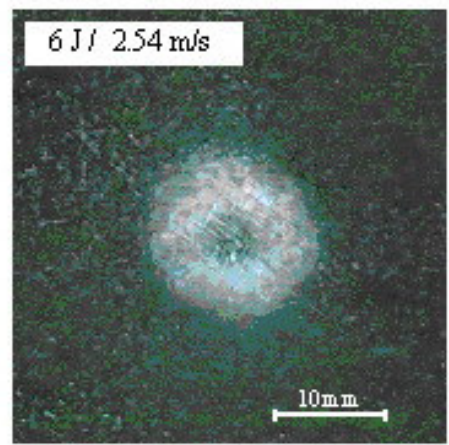

Specimen $2 / 1$

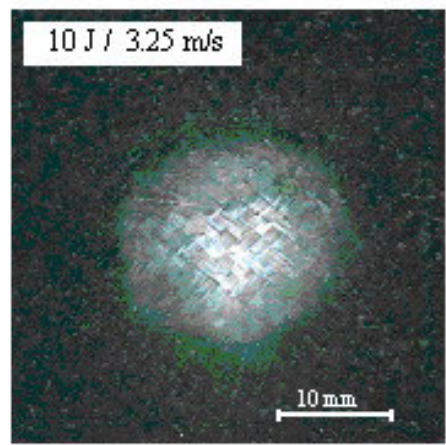

Specimen $2 / 2$

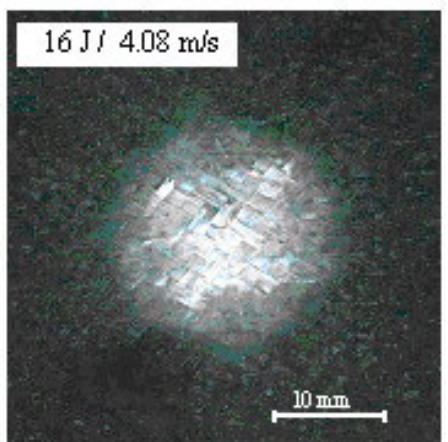

Specimen $2 / 3$

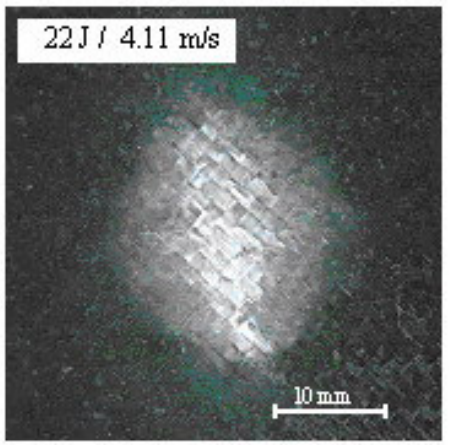

Specimen $2 / 4$

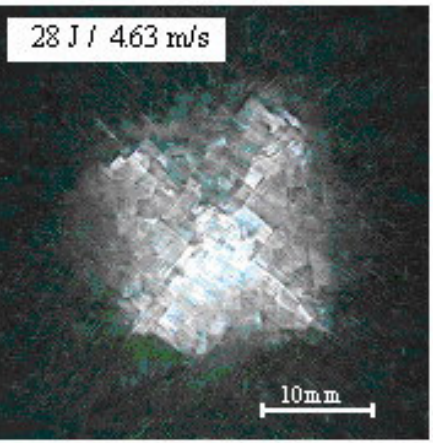

Specimen $2 / 5$

Fig 5. Back face view of woven glass-fiber reinforced composites showing damage modes at respectively

damage and failure at higher energies. At the very low impact energy of about $6 \mathrm{~J}$ obtainable damage is visible. The first signs of damage are matrix cracks, internally or at the back face, which follow the woven pattern of the roving. Regions of debonding and interlaminar damage appear as bright-white zones.

A roughly circular, internal delamination occurs at impact energies of 6,10 and $16 \mathrm{~J}$, whereas in the case of 22 and $28 \mathrm{~J}$ extensive splitting along the fibre direction at the back surface ply resulted in a noncircular damage area. Interlaminar damage occurs at more than one ply interface, but is largest closer to the back-face. With the impacted energy the delamination areas increase gradually. For the $28 \mathrm{~J}$ impacted specimens, this internal delamination becomes diamond shaped with the elongating in the warp and weft. At impact energies of 22 and $28 \mathrm{~J}$, back face fibre damage occurs. Due to impact, bending of the laminates causes back-face fibre tensile failure.

The damaged area of woven glass-fiber composites increases with absorbed energy of $10 \mathrm{~J}$. The lower increase in the area of damage shows that most of the absorbed energy is the result of fibre breakage. Total perforation of the impacted specimens of 2-D woven reinforced plastic composites subjected to the highest energies of $28 \mathrm{~J}$ did not occur, although these specimens suffered fibre failure.

The approach taken in the analysis of the results was also used by Zhou and Davies and Sutherland [13, 10]. The maximum force normalized with thickness to the impact kinetic energy is shown in figure 6. For these data, linear trends are not strong. The limiting of maximum force due to fibre damage at high incident energies is observed.

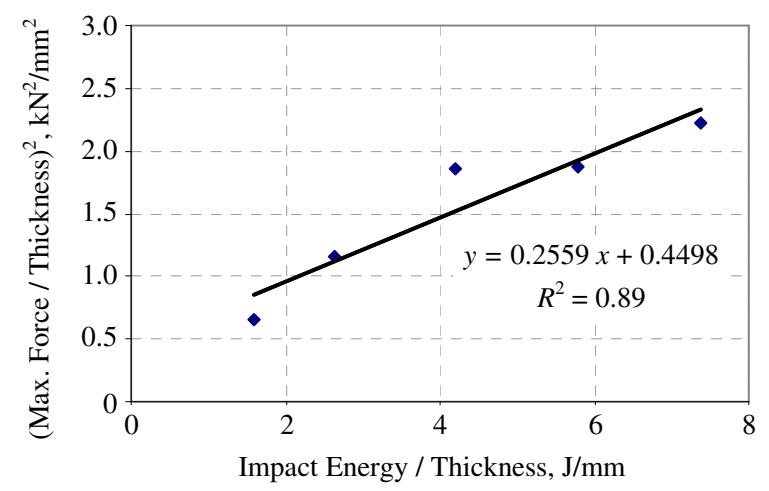

Fig 6. Maximum force normalized with thickness to the impact kinetic energy

For composite materials, especially for glass/epoxy laminates, the case of delamination is important because of low interlaminar shear strength. Making the assumptions that the woven roving composite material is isotropic and that the central delamintion is perfectly circular gives the maximum shear at the mid-plane as:

$$
\sigma_{z r}=\frac{3 P}{4 \pi r t}
$$




$$
\text { Area }=\pi r^{2}=\frac{9}{16 \pi \tau^{2}}\left(\frac{P}{t}\right)^{2}
$$

where $r$ is the delamination radius, $t$ is the laminate thickness, and $P$ is the maximum impact force. The damage area in the form of the delamination would extend to the radius, where $\sigma_{z r}$ exceeds the interlaminar shear strength, $\tau$. High $R^{2}$ values (Fig 7) indicate strong linear trends for the woven roving data.



Fig 7. Damage area plotted against the maximum force normalized with thickness

\section{Conclusions}

Damage prediction is of critical importance in the safe operation of composite structures due to their vulnerability to hidden delaminations, which can occur in composite materials when they are subjected to lowvelocity impact loads. The impact behaviour of woven EGlasslepoxy composite systems has been characterized as the progression of damage with increasing incident energy. Damage to the impacted specimens was complex but was categorized into front face and back face damage and approximately circular internal shear delamination at incident energy. The dominant damage mechanisms for composite were matrix cracking with branching into the adjacent layers, leading to multiple crack front delamination. These are caused by fibre/matrix interface debonding in shear and fracture of matrix resin between the reinforcing fibers. At higher incident energy, significant indentation and back-face fibre damage occurs. The warp and weft in woven fabrics do not allow the formation of a large zone of interlaminar damage with increasingly extensive damage towards the back face. Due to the roughness of the fibers and larger plastic yield zone, the high impact damage resistance of woven fabrics laminates is related to their interlaminar and intralaminar fracture resistance, which is higer than cross-ply laminates. The reduction in the damaged area in the case of woven glass/epoxy composites resulted in a significant improvement in compressive strengths after impact. To assume that for woven reinforced composite systems the response is shear-dominated agrees quite well with the results. The results of this research allow the loads and service life of the widely used composite materials in aircraft structures to be predicted.

\section{References}

1. AITM 1-0010 Fibre reinforced plastics determination of compression strength after impact. - Blagnac Cedex: Airbus Industrie Engineering Directorate, 1999. - $15 \mathrm{p}$.

2. Baker A., Dutton S., Kelly D. Composite materials for aircraft structures. - Reston: American Institute of aeronautics and Astronautics, Inc., 2004. - 599 p.

3. Briscoe B.J., Court R.S., Williams D.R. The effects of fabric weave and surface texture on the interlaminar fracture toughness of aramid/epoxy laminates // Composites Science and Technology. 1993. - Vol 47, No 3. - P. 261-270.

4. Brisco B.J., Williams D.R. Interlaminar fracture toughness of aramid-epoxy laminates // Ibid. - Vol 46, No 3. - P. 277-286.

5. Ebeling T., Hiltner A., Baer E. et al. Delamination failure of a single yarn glass fiber composite // Journal of Composite Materials. - 1997. - Vol 31. - P. 1302 1317.

6. Keršienė N. Žiliukas A. Experimental investigation of low-velocity impact on woven glass-fibrereinforced plastics composites // Mechanika. - 2005. - Vol 56, No 6. - P. 13-17.

7. Schrauwen B., Peijs T. Influence of Matrix Ductility and Fibre Architecture on the Repeated Impact Response of Glass-Fibre-Reinforced Laminated Composites // Applied Composite Materials. Netherlands, - 2002. - Vol 9, No 6. - 331-352 p.

8. Sutherland L.S., Guedes Soares C. Impact characterisation of low fibre-volume glass reinforced polyester circular laminated plates // International Journal of Impact Engineering. - 2005. - Vol 31, No 1. - P. 1-23.

9. Sutherland L.S., Guedes Soares C. Impact tests on woven roving E-glass/polyester laminates // Composites Science and Technology. - 1999. -Vol 59, No 10. - P. 1553-1567.

10. Sutherland L.S., Guedes Soares C. Effects of laminate thickness and reinforcement type on the impact behaviour of E-glass/polyester laminates // Ibid. - No 15. - P. 2243-2260.

11.Xiao J. Y., Bathias C. Fatigue behaviour of unnotched and notched woven glass/epoxy laminates // Ibid. - 1994. - Vol 50, No 2. - P. 141- 148.

12.Zener C., Feshbach H. A method of calculating energy losses during impact // Journal of Applied Mechanics. - 1939. - P. 67-70.

13. Zhou G., Davies G. A. O. Impact response of thick glass fibre reinforced polyester laminates. // International Journal of Impact Engineering. - 1995. Vol 16, No 3. - P. 357-374. 